\title{
Exertional haemoglobinuria: a report on three cases with studies on the haemolytic mechanism
}

\author{
RONALD J. L. DAVIDSON ${ }^{1}$
}

From the Department of Pathology, Queen's College, Dundee

SYNOPSIS Three cases of exertional haemoglobinuria are described. So far, the cause of the under- $-\frac{\overline{0}}{0}$ lying haemolysis in this condition has not been satisfactorily explained, but in the cases described, $\vec{\nabla}$ the haemoglobinuric episodes appeared to be related to traumatic damage to the soles of the feet. ir Experimental studies support the hypothesis that the intravascular haemolysis results from $\mathbb{S}_{\overparen{S}}$ mechanical damage to red cells in the soles of the feet. Furthermore, since adopting remedialo measures, haemoglobinuria has not recurred in any of the patients, although they have continued to pursue their strenuous athletic activities.

The occurrence of haemoglobinuria after strenuous exercise, especially walking and running, has long been recognized (Fleischer, 1881). Haemoglobinaemia of so-called 'physiological' type has recently been observed in apparently healthy athletes after running long distances (Gilligan, Altschule, and Katersky, 1943) and, in some, this is sufficient to saturate the plasma haptoglobins and so cause haemoglobinuria. Thus far the cause of the underlying haemolysis has not been adequately explained.

\section{CASE HISTORIES}

CASE 1 F.M., an 18-year-old schoolboy, complained of passing dark red urine in August 1960 after running five miles on a hard roadway. As a member of a local athletic club, he was in regular, rigorous training and ran, usually on grass, several miles each day. He had further attacks of haemoglobinuria during the early period of investigation, but has had no recurrence during the past three seasons.

CASE 2 A.B., a 21-year-old student, a member of the same athletic club, first passed dark red urine after a road run of several miles at the beginning of the athletic season in 1959. Two days later, his family doctor referred him to another hospital for investigation of 'haematuria'. At that time, clinical examination was negative; the urine gave a negative test for protein and microscopy of the centrifuged deposit showed no abnormality; intravenous pyelography showed normal dye excretion and a normal urinary tract. He had no recurrence of his symptoms until 1961, when he again passed red urine at the end of a cross-country run.

Received for publication 30 December 1963.

Present address: Department of Pathology, Western Infirmary, Glasgow.
CASE 3 W.K., a 22-year-old student, a first class hockey player, complained of passing dark red urine on one occasion in 1961, after a long training session indoors on 6 a hard wooden floor. His only other symptom was that $\risingdotseq$ both heels were painful for at least 24 hours. One further 'experimental' attack was induced by his undertaking rigorous exercise under the same conditions.

POINTS COMMON To ALL CASES In each case the passage of dark red urine, lasting only a few hours after cessation of the provoking exercise, was accompanied by an $\overrightarrow{\vec{O}}$ aching in the muscles of the legs. Case 1, however, 3 complained of sharp stabbing pains in the right inguinal quadrant, described as 'a stitch in the side,' during one haemoglobinuric episode. The previous medical history of each was uneventful. None had significant lumbaro lordosis and repeated clinical examinations were negative:apart from the detection of slight conjunctival icterus on 3 one occasion in case 1 , noted on the day following an attack of haemoglobinuria and gone within 48 hours; the serum bilirubin was $1.2 \mathrm{mg}$. per $100 \mathrm{ml}$. mainly 'indirect'.

\section{PRELIMINARY INVESTIGATIONS}

Each case showed a raised plasma haemoglobin level, a reduced plasma haptoglobin level and haemoglobin in $\mathrm{N}$ the urine. Myoglobinuria was excluded by spectroscopico and electrophoretic examination of the plasma and bycw spectroscopy and chemical testing of the pigmented urine (Blondheim, Margoliash, and Shafrir, 1958).

The following investigations on 'resting' blood samples gave normal results: haemoglobin estimation, leucocytes count, haematocrit, thin film, buffy coat smear; osmotic fragility tests on fresh and incubated samples; auto- -0 haemolysis with and without addition of glucose mechanical fragility test. The blood Wassermann reaction $\frac{\text { के }}{\bar{D}}$ Donath-Landsteiner reaction, Ham's acid serum test,, 
direct Coombs test, and methyl violet preparation for Heinz bodies all gave negative results.

Renal function was normal, assessed by creatinine and urea clearances, blood urea level, intravenous pyelography, chemical and microscopic examination of 'resting' urine.

Liver function tests were normal apart from the one slightly raised serum bilirubin (indirect) level already mentioned.

\section{OBSERVATIONS SUGGESTING A MECHANISM OF HAEMOLYSIS}

During preliminary studies in cases 1 and 2 several facts were noted and thought to be significant: (1) haemoglobinuria occurred only after runs on hard roadways even although the distance covered was only about one mile; (2) running under such conditions caused marked engorgement of the veins of the feet and a feeling of 'burning' in the soles; (3) both runners could run more than five miles on a cinder or grass track without evidence of haemoglobinuria; and (4) case 1, a powerful runner, had a heavy and rather stamping stride.

These observations and the fact that case 3 showed haemoglobinuria after exercise only if on a hard floor, suggested the intravascular haemolysis might well be related to a mechanical effect on the blood within the vessels of the soles of the feet. Possible factors leading to such excessive mechanical traumatization were considered to be $(a)$ hardness of running surface, $(b)$ running distance, $(c)$ 'heaviness' of stride, $(d)$ protective adequacy of footwear, and (e) temperature increase in soles of the feet. General metabolic disturbances resulting from exertion such as $(a)$ increase in general body temperature, $(b)$ changes in blood sugar level, and (c) alteration in blood $p \mathrm{H}$ were thought to be unlikely causes.

The following experiments were devised to assess the possible significance of these factors in cases 1 and 2. Both, matched with a control runner, a trained athlete of similar age, height, and weight, undertook two test tuns; a three-mile run on a hard roadway, and, one week later, a three-mile run on a grass track. The following tests and measurements were carried out on each runner and his control before and after the test runs.

TRAUMATIC HAEMOLYSIS This was measured by a method in vitro (sic) employing cork and felt insoles fitted with narrow, soft, compressible polyvinylchloride tubes (hereafter referred to as P.V.C.) on the forefoot and heel portions as shown (Fig. 1). Immediately before the test runs, blood from each of the runners was withdrawn into heparinized containers from which samples of known volume were carefully delivered by a Pasteur pipette into the

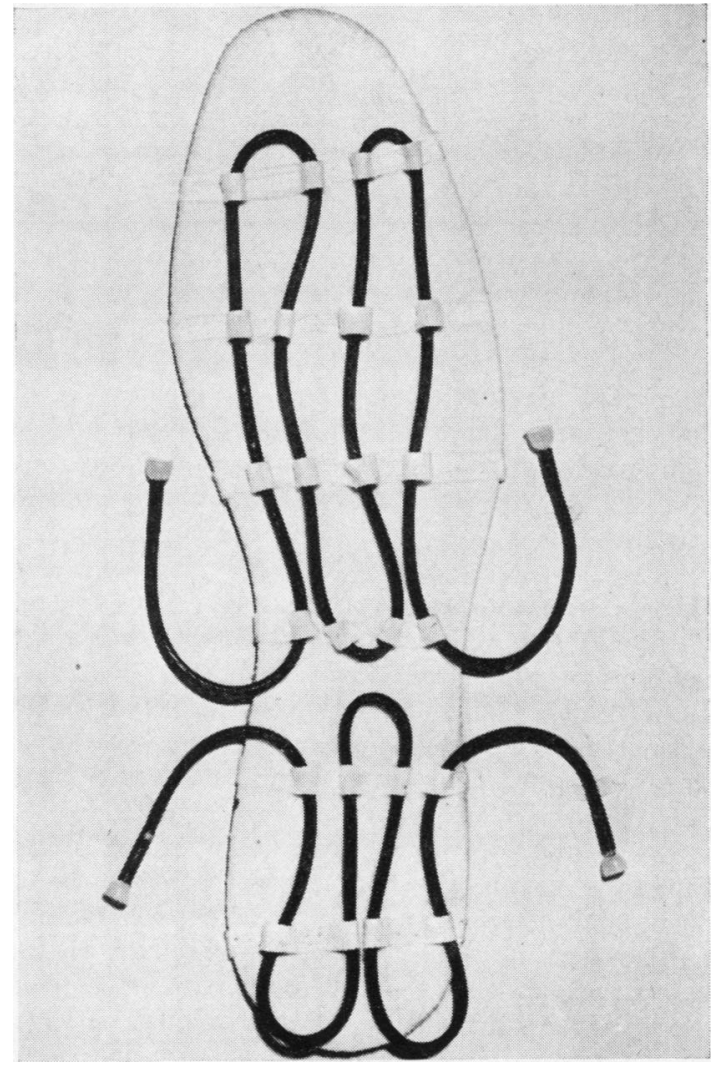

FIG. 1

tubes in such a way as to avoid the formation of bubbles of air. These were then sealed by plastic stoppers and wax and the insoles inserted into the runner's shoes with tubes uppermost. After the test runs, the samples were drained from the circuits and centrifuged. The haemoglobin content of the supernatant plasma was estimated as oxyhaemoglobin in an EEL photoelectric colorimeter and the degree of traumatic haemolysis expressed as a percentage haemolysis.

The blood samples were so arranged that each runner had his own blood in the P.V.C. tubes of his right insole and his partner's blood in the left insole. This distribution eliminated any otherwise unrecognized variation in the fragility of any of the blood samples to the conditions of the experiment. In addition, each runner had a sample of his own blood within a sealed P.V.C. tube attached to the tibial surface of his right leg. Plasma from this sample was used for control readings in the traumatic haemolysis test and for comparative temperature recordings.

The results of this test (Table I) show that the 
TABLE I

RAUMATIC HAEMOLYSIS (\% HAEMOLYSIS)

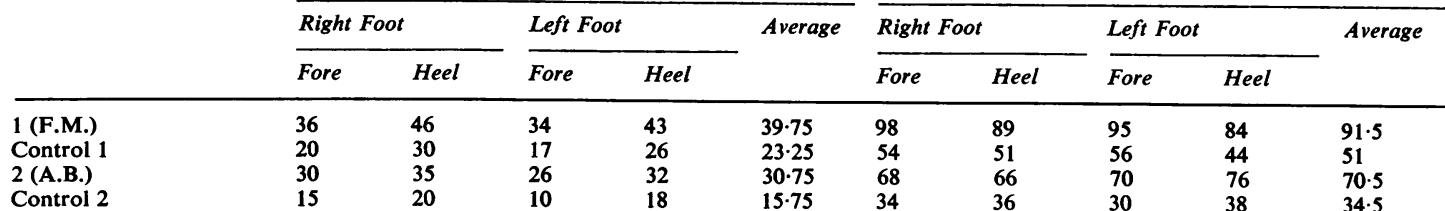

degree of traumatic haemolysis is greatest in all subjects after running on the roadway and is significantly greater in both patients than in their controls. All runners haemolysed their own and the control's blood to approximately the same degree.

PLASMA HAEMOGLOBIN ESTIMATIONS The plasma haemoglobin level of all four subjects was estimated before and after each run. Using the benzidene method, modified by Crosby and Furth (1956), the plasma levels in 40 normal blood donors were found to range from 1.5 to $5 \mathrm{mg}$. with a mean of $3.2 \mathrm{mg}$. per $100 \mathrm{ml}$.

The results (Table II), paralleling those of the traumatic haemolysis test, show that the plasma haemoglobin increment in all subjects is significantly greater after running on the roadway than on the grass track and is greater in both patients than in their concrols. In fact, the plasma of both patients, obtained after the road run, was pink on naked-eye examination.

\section{TABLE II}

PLASMA HAEMOGLOBIN CONCENTRATION (mg./100 ml.)

\begin{tabular}{llllll}
\multirow{2}{*}{ Case } & \multicolumn{2}{l}{ Test Run on Grass } & & \multicolumn{2}{c}{ Test Run on Road } \\
\cline { 2 - 3 } \cline { 5 - 6 } & Before & After & & Before & After \\
\hline 1 (F.M.) & 3.5 & 5.5 & & 4.8 & 48.2 \\
Control 1 & 4.0 & 5.0 & & 5.5 & 7.5 \\
2 (A.B.) & 3.2 & 4.0 & & 2.5 & 25.5 \\
Control 2 & 2.8 & 4.0 & & 2.0 & 4.5
\end{tabular}

PLASMA HAPTOGLOBIN BINDING CAPACITY The haptoglobin levels were estimated by the method of Smith (1960). In a control series of 40 blood donors, the binding capacity was found to range from 80 to $140 \mathrm{mg}$. with a mean of $108 \mathrm{mg}$. per $100 \mathrm{ml}$.

The results (Table III) show a significant reduction in the binding capacity of the plasma of both patients after the road run only, commensurate with the rise in plasma haemoglobin level found under these conditions.

TEMPERATURE CHANGES The oral and axillary temperatures were measured by an ordinary clinical thermometer. The temperature of the soles of the feet
TABLE III

PLASMA HAPTOGLOBIN-COMBINING POWER (mg./100 ml.)

\begin{tabular}{lccccc} 
Case & \multicolumn{2}{c}{ Test Run on Grass } & & \multicolumn{2}{c}{ Test Run on Road } \\
\cline { 2 - 3 } \cline { 5 - 6 } & Before & After & & Before & After \\
\hline 1 (F.M.) & $20-30$ & $20-30$ & $20-30$ & - \\
Control 1 & $100-110$ & $100-110$ & & $100-110$ & $100-110$ \\
2 (A.B.) & $70-80$ & $70-80$ & & $70-80$ & $30-40$ \\
Control 2 & $90-100$ & $90-100$ & $90-100$ & $90-100$
\end{tabular}

and that of the blood samples within the P.V.C. tubes used in the traumatic haemolysis tests were recorded by an electric Universal thermometer

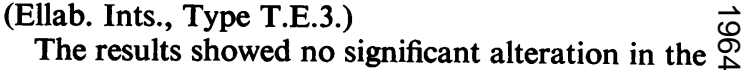
resting or post-exercise recordings.

BLOOD FILM AND INDICES, SALINE OSMOTIC FRAGILITY, AND AUTOHAEMOLYSIS TESTS These investigations, carried out according to Dacie (1956) on resting and post-exercise samples, gave normal results in all four subjects.

BLOOD $p \mathrm{H}$ AND SUGAR ESTIMATIONS The $p \mathrm{H}$ values of venous blood were recorded on an E.E.I. $p H$ meter and blood sugar levels estimated by the method of Hoffmann (1937). Resting and post-exercise values in each subject were normal and showed no significant deviation.

URINE EXAMINATION The 'resting' urine of all subjects was chemically and microscopically normal.

After running on the grass track. the urine of both patients and their controls showed a trace of protein; the centrifuged deposits contained occa- or sional hyaline casts; haemoglobin was not detected.

After the run on the roadway, the urine of case 1 was dark red, and showed heavy proteinuria; the centrifuged deposit contained numerous hyaline and occasional granular casts; haemoglobin was detected on spectroscopic and chemical testing. Under the same conditions, the urines of case 2 and both controls were of normal colour but showed moderate proteinuria; the centrifuged deposits contained occasional hyaline casts; no haemoglobin was detected. 


\section{DISCUSSION}

CLINICAL ASPECTS Since Fleischer (1881) first described 'Marsch Hämoglobinurie' in a young soldier, some 80 cases, mainly young male subjects, have been reported (Wintrobe, 1961). Its occurrence in females has only twice been recorded (Vogt, Vogel, and Geiseler 1943; Gilligan and Altschule, 1950). This age and sex distribution may be explained by the more frequent participation of young males in severe prolonged exertion.

The presenting, and sometimes the only complaint, is the passage of red urine. This alarming symptom may be accompanied by nausea, abdominal cramps, aching in the back or legs, or 'a stitch in the side'.

Clinical examination is usually negative although about half the recorded cases have shown lumbar lordosis. Palpable enlargement of the spleen has been noted in three cases (Lang and Braun, 1931; Gilligan and Blumgart, 1941; Palmer and Mitchell, 1943) and enlargement of the liver in two cases Gilligan and Blumgart, 1941 ; Porges and Strisower, 1914). Transient jaundice, as in case 1 , has been observed in three cases (Gilligan and Blumgart, 1941; Lubran and Sakula, 1949). Anaemia is rare and if present is usually mild. Morphological evidence of red cell damage is not a feature but Watson and Fischer (1935) noted poikilocytes and occasional 'four-leaf clover' cells in the peripheral blood of their patient after exercise.

This form of 'paroxysmal' haemoglobinuria is clinically recognized by its characteristic relation to physical exertion in the upright posture, usually walking or running, each 'paroxysm' usually lasting only a few hours after cessation of the causal exertion. Haemoglobinuric episodes may recur in the same individual for as long as seven years (Fisher and Bernstein, 1940) and although generally regarded as being self-limiting, many of the apparently 'spontaneous' remissions may be due to avoidance, intentional or unintentional, of the provoking exertion.

VIEWS ON AETIOLOGY So far this has eluded satisfactory explanation. Any hypothesis must account for (a) the apparently intravascular haemolysis with haemoglobinuria, $(b)$ the relationship to the erect posture, and $(c)$ the resultant haemoglobinuria.

Views based on a haemolytic mechanism The haemolytic mechanism was regarded by Fleischer (1881) as due to 'a primary blood disease' and later Lichtwitz (1916) postulated an underlying defect of the red cell stroma; local red cell destruction was thought to occur in the spleen (Porges and Strisower, 1914) in the veins of muscles (Foerster, 1919), or in the renal vessels (Chvostek, 1894; Schellong, 1923; Witts, 1936); the question of $\mathrm{CO}_{2}$ as a haemolytic agent was raised by MacKenzie (1929), while Lubran and Sakula (1949) believed that the excessive haemolysis resulted from abnormally fragile red cells released by splenic contraction during exercise. These theories have largely been disproved by subsequent experiment and also by the fact that the suggested mechanisms would obtain in other forms of severe exertion not undertaken in the erect posture, such as swimming or cycling.

The haemolysis was later regarded as 'physiological' and analogous to the albuminuria of exercise (Gilligan et al., 1943), while Martin and Kilian (1959) and Flatmark (1963) have suggested that the condition is 'a transient acquired erythropathia'. Having demonstrated a significant fall in the properdin titre in the blood of a patient during and after exercise, Martin and Kilian concluded that the patient's red cells, 'damaged' in some unknown way by exercise, had an increased susceptibility to haemolysis by the properdin system.

Views based on a renal mechanism The early concepts of the mode of excretion of haemoglobin by the kidneys, based on theories of tubular reabsorption (Yuile, 1942), led several workers to explain exercise haemoglobinuria on the basis of a non-specific tubular defect (Pare and Sandler, 1954) or an alteration of glomerular permeability (Miller and McDonald, 1951).

It is now generally accepted, however, that the renal excretion of haemoglobin only occurs after saturation of the plasma haptoglobin, the binding capacity of which determines the renal threshold (Laurell and Nyman, 1957; Allison and ap Rees, 1957; Lathem, 1959).

THE PRESENT STUDY The constant relationship of the haemoglobinuric episodes in each of the three patients to the 'hardness' of the running surface appeared significant. This association had in fact been noticed in the past (Attlee, 1937) in two public schoolboys "who were in the habit of playing strenuous school games and running long distances on grass, without symptoms, but attacks followed immediately after running on a hard road'. The author concluded: 'It seems unlikely that this sequence of events can be nothing more than a coincidence, but it is difficult to see the connexion.'

That this is something more than a mere coincidence is shown by the finding of excessive haemolysis not only in the patients' circulating blood, but also that in the closed compressible tubes under their feet. As the degree of haemolysis in the P.V.C. tubes is directly related to the amount of mechanical trauma sustained by the soles of the 


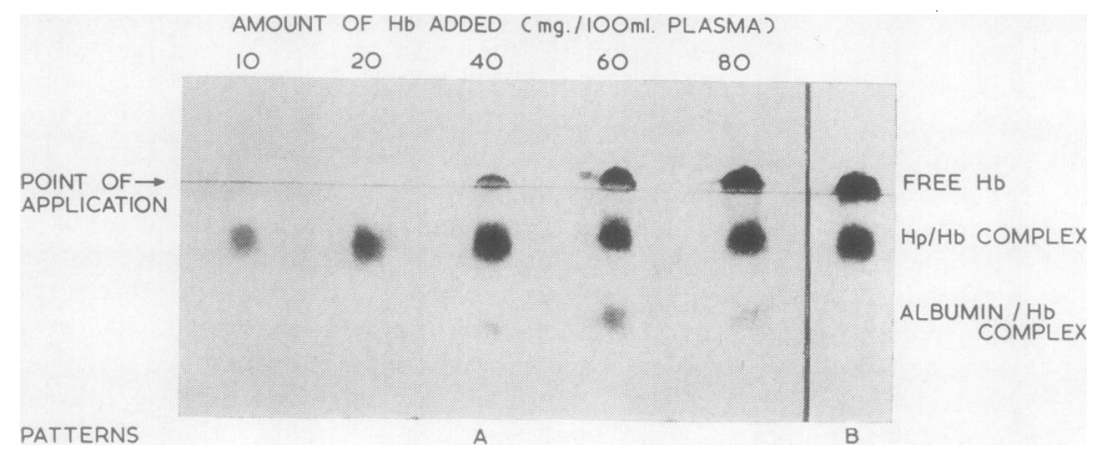

FIG. 2

feet, it seems highly probable that the same factor also operates in vivo and induces the pre-haemolytic red cell damage.

This explanation of the haemolytic mechanism would also account for the greater increments of haemolysis recorded in both patients after the road runcompared with the controls, the more powerful but running action of the former thus predisposing them to greater mechanical red cell damage. Further, if not final, support for this hypothesis is that the haemoglobinuric episodes ceased in all three patients after remedial measures were applied. Thus case 1 altered his style of running and took to wearing running shoes with additional resilient insoles. Since adopting these measures two seasons ago, he has had no recurrence of the haemoglobinuria even although his present training schedule includes running an average of 70 miles each week under cross-country conditions.

In this study, the finding of a reduced haptoglobinbinding capacity in case 1 and 2 is interpreted as being due to an increase in the rate of removal of haptoglobin secondary to the repeated episodes of haemolysis. Under these circumstances, the chronic state of hypohaptoglobinaemia may be regarded as increasing these patient's susceptibility to haemoglobinuria.

The plasma haptoglobin-binding patterns of case 1 are shown in Figure 2. Pattern A (before exercise) shows the lower than normal haptoglobin level; pattern B (after the road run) clearly demonstrates that haptoglobin saturation has occurred, the 'free' or unbound haemoglobin in the plasma being subsequently excreted in the urine.

These findings support the current plasmabinding theory of haemoglobinuria and emphasize that in exercise haemoglobinuria the passage of haemoglobin is a passive process secondary to $\mathcal{E}^{-}$ intravascular haemolysis.

I wish to thank Professor A. C. Lendrum and Dr. H. B. Goodall for their helpful criticism and for reviewing the manuscript, Dr. A. A. Kirkland for referring case 1 for investigation, and Mr. R. Smith, Mr. T. King, and Miss. I. Bowman for special technical assistance.

I also gratefully acknowledge the keen cooperation of the patients, expecially F.M., and the control runners enlisted from the Hawkhill Harrier Club, Dundee.

\section{REFERENCES}

Allison, A. C., and ap Rees, W. (1957). Brit. med. J., 2, 1137.

Attlee, W. H. W. (1937), Lancet, 1, 1400.

Blondheim, S. H., Margoliash, E., and Shafrir, E. (1958). J. Amer. med. Ass., 167, 453.

Chvostek, F. (1894). Uber das Wesen der Paroxysmalen Hämoglobin urie. Deuticke, Leipzig and Vienna.

Crosby, W. H., and Furth, F. W. (1956). Blood, 11, 380.

Dacie, J. V. (1956). Practical Haematology, 2nd ed. Churchill, London.

Fisher, A. M., and Bernstein, A. (1940). Bull.Johns Hopk. Hosp., 67, 457.

Flatmark, T. (1963). Acta med. scand., 173, 307.

Fleischer, R. (1881). Ber. klin. Wschr., 18, 691.

Foerster, A. (1919). Münch. med. Wschr., 66, 554.

Gilligan, D. R. and Altschule, M. D. (1950). New Engl.J. Med.,243, 944.

,-- , and Katersky, E. M. (1943). J. clin. Invest., 22, 859.

, and Blumgart, H. L. (1941). Medicine (Baltimore), 20, 341.

Hoffmann, W. S. (1937). J. biol. Chem., 120, 51.

Lang, K., and Braun, A. (1931). Z. klin. Med., 118, 374.

Lathem, W. (1959). J. clin. Invest., 38, 652.

Laurell, C. B., and Nyman, M. (1957). Blood, 12, 493.

Lichtwitz, L. (1916). Berl. klin. Wschr., 53, 1233.

Lubran, M., and Sakula, J. (1949). Lancet, 1, 435.

Martin, H. and Kilian, P. (1959). Folia haemat. (Frankfurt), 4, 92.

MacKenzie, G. M. (1929). Medicine (Baltimore), 8, 159.

Miller, J. H., and McDonald, R. K. (1951). J. clin. Invest., 30, 1033. Palmer, R. A., and Mitchell, H. S. (1943). Canad. med. Ass. J., 49, 465. Pare, C. M. B., and Sandler, M. (1954). Lancet, 1, 702.

Porges, O., and Strisower, R. (1914). Dsch. Arch. klin. Med., 117, 13.

Schellong, F. (1923). Z. ges. exp. Med., 34, 82.

Smith, I. (1960). Chromatographic and Electrophoretic Techniques, vol. 2. Heinemann, London.

Vogt, H., Vogel, H., and Geiseler, G. (1943). Dsch. Arch. klin. Med., $191,488$.

Watson, E. M., and Fischer, L. C. (1935), Amer. J. clin. Path., 5, 151. Wintrobe, M. M. (1961). Clinical Haematolosy, 5th ed. Kimpton, London.

Witts, L. J. (1936). Lancet, 2, 115

Yuile, C. L. (1942). Physiol. Rev. 22, 19. 